\title{
POESÍA Y SABER EN DANTE ALIGHIERI
}

Joaquín Barceló

\section{RR} Cuando Dante y Virgilio se hallan ante las puertas de la ciudad de Dite, dentro de la cual se castigan, no ya los pecados de incontinencia, sino aquellos más graves de bestialidad y malicia, chocan con la oposición de las Erinias y de Medusa, que quieren impedir la entrada de ambos poetas a la "tierra desconsolada". Nunca, durante toda la peregrinación infernal, fue tan difícil para Dante el acceso a una región del mundo condenado; y hasta tal punto es así, que los conjuros de Virgilio se revelan esta vez ineficaces y es necesaria la especial intervención de un enviado del cielo para que se abran a ambos caminantes las puertas de la ciudad maldita y pueda Dante proseguir su misterioso y sagrado viaje. La atmósfera de la escena en que el poeta relata este episodio es no sólo de alta intensidad dramática sino también de oscura solemnidad. Y en este punto se intercala un llamado al lector para que no pierda de vista el significado alegórico de la relación fantástica que se le ofrece:

O voi ch'avete li'ntelletti sani, mirate la dottrina che s'asconde sotto il velame de li versi strani ${ }^{1}$

Hay también, en otros lugares de la obra de Dante, llamados similares al lector, en que éste es invitado a no permanecer detenido en el goce de la belleza de la creación poética, sino a avanzar hacia la comprensión de su significado doctrinal, de su ragione ${ }^{2}$. Con particular insistencia recuerda el poeta la "doctrina" que bajo las bellas formas de la poesía se oculta. Dichas amonestaciones eran más o menos superfluas para el lector culto medieval, quien estaba habituado a leer no sólo a los poetas cristianos, sino también a los clásicos de la Antigüedad pagana, pasados por el tamiz de la interpretación alegórica. Para la sensibilidad poética moderna, en cambio, el procedimiento medieval resulta falso y, en cierto modo, escandaloso. Que la poesía deba necesariamente tener un fondo doctrinal es una tesis que no nos parece aceptable sin más. Por esta razón, procuraremos poner en evidencia en estas páginas cómo entendía Dante la relación entre lo que nosotros llamamos poesía y la doctrina contenida en ella, y en qué fundaba la necesidad de esta extraña cópula entre dos realidades que se nos aparecen independientes y autónomas.

Referente al primero de los problemas señalados, poseemos dos textos de Dante que lo tratan en forma expresa y que se encuentran en el Convivía y en la Epístola a

$1 \quad$ Infl. Ix, 61-63: “¡ Oh vosotros, los que tenéis vuestros entendimientos sanos, atended a la doctrina que se esconde bajo el velo de los extraños versos!”.

$2 \quad C f r$. Conv. I, I, 14 y la tornata de la primera canción de la misma obra (Conv. II, canz. 5361). 
Cangrande della Scala ${ }^{3}$. El Convivía fue con cebido originariamente como una colección de catorce canciones y sus respectivos comentarios, de las que sólo tres llegaron a ser reunidas y explicadas. La Epístola a Cangrande representa, en cambio, una suerte de introducción a la lectura de la Divina Commedia, con la que Dante quiso facilitar a su amigo la comprensión de la tercera parte de la obra, del Paradiso. Ambos textos se refieren, pues, a obras poéticas concretas, en las que quiere Dante poner en particular relieve la cuestión de la doctrina en ellas contenida.

Interesa especialmente seguir el desarrollo del problema en el Convivio, donde se encuentra elaborado en forma más explícita. El poeta compara las canciones por él reunidas con los alimentos que se sirven en un verdadero banquete. Pero che più profittabile sia questo mio cibo, escribe, prima che vegna la prima vivanda voglio mostrare come mangiare si dee 4 . Se trata, pues, de una exposición metódica preliminar que enseña el modo de leer la poesía; porque no es suficiente el mero quedar impresionado por la belleza del poema, sino que es necesario, además, ser capaz de entender su significado. El método consiste en que la interpretación del poema, que en este caso va a ser llevada a cabo por el mismo Dante, atiende tanto al sentido literal como al sentido alegórico. Para explicar lo que debe entenderse por ello, recurre el poeta al cuádruple sentido en que, según la doctrina tradicional, deben los teólogos interpretar las Sagradas Escrituras. Este procedimiento exegético reconoce, en casi todos los pasajes de la Biblia, cuatro planos diferentes de la manifestación de la verdad, que son: 1) el sentido literal o histórico, esto es, el significado inmediato de la narración, aquello que se dice que ha ocurrido; 2) el sentido alegórico, que consiste, para los teólogos, en aquel significado oculto por el relato literal y que se refiere a algún misterio de la fe; 3 ) el sentido moral, que desencubre alguna velada doctrina sobre la conducta que han de llevar los hombres, y 4) el sentido anagógico, que hace vislumbrar alguna verdad referente a la vida del Más Allá. Se puede apreciar de inmediato que los tres últimos sentidos, es decir, el alegórico, el moral y el anagógico, poseen un rasgo común, a saber, que todos ellos están ocultos bajo el velo del sentido literal, de manera que los tres pueden, en general, ser considerados como alegoría en sentido amplio; y así los considera también Dante en la Epístola arriba mencionada.

Tampoco se le oculta a nuestro poeta que no siempre pueden estar presentes los cuatro sentidos en la poesía. Sólo los significados literal y alegórico (en sentido estricto) no pueden faltar; ellos son elementos esenciales de la obra poética, y por esta razón las canciones del Convivio serán interpretadas sólo literal y alegóricamente, recurriéndose a los otros sentidos sólo allí donde sea oportuno.

Importa, sin embargo, establecer claramente qué entiende Dante por sentidos literal y alegórico, no ya en referencia a la teología sino en conexión con la poesía misma. El poeta define el sentido literal como quello che non si stende più oltre che la

Conv. II, cap. I; Epist. XIII, 7, 20-22.

Conv. II, I, 1: "A fin de que sea más provechoso éste mi alimento, antes que se sirvan las primeras viandas quiero mostrar cómo se las ha de comer". 
lettera de le parole fittizie, si come sano le favole de li poeti ${ }^{5}$. Estas palabras ficticias de las fábulas poéticas son determinadas a continuación como una "bella mentira". Aquí se muestra ya una diferencia entre el sentido literal de la poesía y el de la teología, pues para el teólogo es la narración literal en la Escritura siempre verdadera, aun cuando una u otra vez pueda presentarse en forma metafórica. El sentido literal de la poesía, en cambio, es esencialmente ficción y mentira. Pero si consiste en "palabras ficticias" y "bellas mentiras", se alude con ello por vía negativa a una supuesta verdad que no se identifica con el relato literal; y esta verdad está presente en el significado alegórico, que Dante define como quello che si nasconde sotto'l manto di queste favole, ed è una veritade ascosa sotto bella menzogna ${ }^{6}$.

Aquí se presenta, sin embargo, una nueva diferencia entre la exégesis teológica y la interpretación poética; pues en tanto que para los teólogos el significado alegórico debe revelar un misterio de la fe, para el poeta la verdad oculta bajo el velo de la literalidad puede referirse a cualquier dominio del saber humano. En esto Dante no hace sino continuar la tradición medieval, que había interpretado desde este punto de vista la totalidad de la poesía pagana que le era conocida ${ }^{7}$. Y mientras en su Epístola a Cangrande explica el sentido alegórico en forma completamente teológica, en el Convivio aduce un ejemplo mucho más significativo y sugerente; la alegoría, escribe, debe entenderse si come quando dice Ovidio che Orfeo facea con la cetera mansuete le fiere, e li arbori e le pietre a sè muovere; che vuol dire che lo savio uomo con lo strumento de la sua voce faria mansuescere e umiliare li crudeli cuori, e faria muovere a la sua volontade coloro che non hanno vita di scienza e d'arte: e coloro che non hanno vita ragionevole alcuna sano quasi come pietre ${ }^{8}$.

No es, pues, el poema una creación de valor puramente estético, sino una obra doctrinal que ha revestido el ropaje de la bella forma literaria. Pero aquí surge de inmediato la pregunta siguiente: si lo esencial es enseñar una verdad, ¿por qué es necesario que ésta se halle oculta bajo el sentido literal de la poesía y no se muestre patente, como ocurre en las obras didácticas o científicas? En otras palabras: si la belleza no tiene un valor en sí misma, sino que debe justificar su existencia en un trasfondo doctrinal, ¿por qué existen, en general, la poesía y el arte? Dante plantea la pregunta

5 Conv. II, I, 3: "aquél que no va más allá de la letra de las palabras ficticias, como son las fábulas de los poetas".

6 Conv. II, I, 3: "aquél que se esconde bajo el manto de estas fábulas y es una verdad oculta bajo una bella mentira".

7 En particular vale esta afirmación para la obra de Virgilio, que tan decisivamente influyó sobre la formación de Dante como poeta. Cfr. D. Comparetti, Virgilio nel Medio Evo, 1872.

8 Conv. II, I, 3: "así como cuando Ovidio dice que Orfeo con su cítara amansaba a las fieras y hacía que los árboles y las piedras se moviesen hacia él; lo que significa que el hombre sabio podría, con el instrumento de su voz, amansar y humillar los corazones crueles, y haría moverse a voluntad a aquellos que no poseen vida de ciencia y de arte; pues los que no tienen vida racional alguna son como las piedras". 
en el Convivio, pero deja la respuesta para el penúltimo tratado de la obra ${ }^{9}$, que, sin embargo, nunca llegó a escribir.

En la Divina Commedia encontramos una parte de la respuesta a dicha pregunta. En el Canto IV del Paradiso, Beatriz debe resolver una duda de Dante; el poeta ha sido informado de que todos los espíritus bienaventurados tienen su sede en el Empíreo. ¿Cómo es, entonces, que Platón enseñó en el Timeo que las almas de los hombres proceden de los astros y que retornan a ellos después de la muerte de los cuerpos? ${ }^{10}$. Por otra parte, también a Dante se le muestran los espíritus, contrariamente a la verdad recién averiguada y en conformidad más bien con la doctrina platónica, en las diferentes esferas de los planetas. ¿Por qué? Beatriz explica:

Casi parlar conviensi al vostro ingegno, pero che solo da sensato apprende ció che fa poseía d'intelletto degno ${ }^{11}$.

Con la filosofía aristotélico-tomista, aceptaba Dante la tesis de que el conocimiento humano empieza en la aprehensión de la realidad sensible y desde allí se eleva a la intelección de lo abstracto y universal. Por esta razón, es también necesario que una doctrina sea presentada en forma sensible, para que el entendimiento, a partir del dato concreto, pueda alcanzar el saber abstracto que ella quiere comunicar. Es también en esta forma cómo está expuesta la verdad contenida en las Sagradas Escrituras, y la Biblia condesciende a esta limitación humana "y pies y manos atribuye a Dios, si bien otra cosa entiende" 12 . De este modo, es posible que la doctrina contenida en el Timeo signifique algo distinto de lo que las palabras en forma inmediata dejan entender:

\section{E forse sua sentenza e d'altra guisa che la voce non suona, ed esser puote con intenzion da non esser derisa ${ }^{13}$.}

Así, pues, es necesario investigar cuál es la alegoría contenida en esta tesis del Timeo; si ella se refiere al influjo de las estrellas sobre las almas humanas (doctrina

11 Par. IV, 40-42: "Hablar así es lo adecuado a vuestro entendimiento, puesto que él sólo aprehende del dato sensible lo que luego hará digno de intelección".

12 Par. IV, 43-45: "Per questo la Scrittura condescende / a vostra facultate, e piedi e mano / attribuisce a Dio, ed altro intende". La misma tesis en Tomás de Aquino, Summa theol. I, 1, 9: "Conveniens est sacrae Scripturae divina et spiritualia sub similitudine corporalium tradere. Deus enim omnibus providet secundum quod compe tit eorum naturae. Est autem naturale homini ut per sensibilia ad intelligibilia veniat: quia omnis nostra cognitio a sensu initium habet. Unde convenienter in sacra Scriptura traduntur nobis spiritualia sub metaphoris corporalium ..." Cfr., además I, 1, 10 ad 3.

13 Par. IV, 55-57: "Y tal vez su doctrina es de otra guisa que como suenan las palabras, y es posible que no sea irrisorio su sentido". 
astrológica aceptada por Dante), ha sido encontrada la verdad; si, en cambio, no se logra llevar a cabo esta correcta interpretación del texto platónico, es fácil caer en el error del paganismo consistente en la deificación de los astros ${ }^{14}$. Este ejemplo concreto de interpretación alegórica nos hace ver hasta qué punto ella era importante para el enfrentamiento del hombre de la Edad Media cristiana con las creaciones literarias de la Antigüedad; es característico, por otra parte, cómo para Dante no sólo la poesía, sino también la filosofía pagana requieren de una interpretación alegórica, con el fin de develar la verdad a todo precio.

Si este pasaje del Paradiso nos ofrece una respuesta a la pregunta por el significado de la alegoría en la creación poética, queda todavía una dimensión del problema que, hasta donde estoy informado, no ha sido aún señalada. Se trata, ciertamente, de un aspecto de la cuestión que Dante no indica en manera alguna en su obra, pero que puede inferirse de los planteamientos de Tomás de Aquino, a quien el poeta siguió fielmente en todos los grandes problemas filosóficos.

Si consideramos nuevamente el pasaje aludido del Paradiso, observamos que establece, entre las parejas de conceptos "sentido literal" -"sentido alegórico" y "conocimiento sensible"- "conocimiento intelectual”, una relación de analogía. La poesía presenta, en primer término, en forma inmediata, su sentido literal, para que el lector atento infiera de él su sentido alegórico; de la misma manera, en el acto de conocimiento se aprehende primero el dato sensible para remontarse, a partir de él, a la intelección de lo abstracto. Hay, pues, por una parte, una correspondencia entre el sentido literal de la poesía y la realidad aprehendida por los sentidos, y, por la otra, una correspondencia entre el sentido alegórico y el saber abstracto y universal. El análisis de los conceptos no hace sino confirmar la analogía constatada. La sensación da a conocer solamente lo particular; es, como lo pone Aristóteles, la aprehensión de un "aquí" y un "ahora". La intelección, en cambio, se refiere, como tal, únicamente a lo universal e ignora, en sentido propio, lo particular ${ }^{15}$. Del mismo modo, la narración literal, que constituye el "dato" inmediato de la experiencia de la poesía, nos pone frente a situaciones particulares concretas (por ejemplo, Dante Alighieri florentino recorriendo, en una fecha histórica determinada, los reinos ultramundanos en compañía de determinados espíritus, en medio de determinados paisajes y gozando de determinados espectáculos), en tanto que el sentido alegórico nos presenta una verdad de valor universal y abstracto (en nuestro caso, "el hombre entregado a la justicia que premia y castiga según sus merecimientos

14 Par. IV, 58-63.

15 Summa theol., I, IIae, 2, 6: "Et ideo sensus, qui est vis corporalis, cognoscit singulare, quod est determinatum per materiam: intellectus vero, qui est vis a materia absoluta, cognoscit universale, quod est abstractum a materia, et continet sub se infinita singularia"; I, 12, 4: "Sensus non cognoscit nisi singularia"; I, 86, I: "Intellectus noster directe non est cognoscitivus nisi universalium”. 
o desmerecimientos sobre la base de su libertad de arbitrio") ${ }^{16}$, que no está en sí misma comprometida con las vicisitudes y peripecias de que nos da cuenta la narración literal.

El conocimiento de lo particular, que el hombre alcanza por vía de la experiencia sensorial, es rico en notas diversas que acompañan a la cosa concreta percibida; no así el conocimiento de lo universal, que, para alcanzar la generalidad que le es propia, debe renunciar a dicha riqueza de notas y hacerse abstracto, puesto que aprehende sólo la forma o especie, que excluye, a su vez, a la materia individual y todas sus determinaciones. "Aquella cosa que es un hombre", escribe Tomás, "tiene en sí algo que la humanidad no posee" ${ }^{17}$. Ni el intelecto puede aprehender directamente, como tal, las cosas en la riqueza de su singularidad, ni los sentidos pueden proporcionar por sí mismos un conocimiento universal de sus objetos. Pero la universalidad constituye la nota distintiva del más alto saber, y la tragedia del conocimiento humano estriba en que la universalidad sólo se logra mediante un progresivo empobrecimiento de lo conocido, gracias al sacrificio de aquellas notas que constituyen la ilimitada variedad bajo la que se nos ofrece la realidad sensible. El hombre permanece así esencialmente limitado e imperfecto como sujeto cognoscente. De una u otra manera, la Edad Media se hizo cargo de esta limitación, ya que vio que ella sólo comenzaba a ser superada en la forma del conocimiento del ángel. En el mundo de las creaturas, los ángeles son los únicos seres que aunan el conocimiento de lo singular y de lo universal en un solo acto cognoscitivo. Tomás de Aquino afirma: Sicut homo cognoscit diversis viribus cognitivis omnia rerum genera, intellectu quidem universalia et immaterialia, sensu autem singularia et corporalia; ita angelus per unam intellectivam virtutem utraque cognoscit ${ }^{18}$.

16 Esta determinación del sentido alegórico de la Divina Commedia procede del mismo Dante, Epist. XIII, 8, 22: "Si vero accipiatur opus allegorice, subiectum est homo prout merendo et demerendo per arbitrii libertatem iustitie premiandi et puniendi obno xius est".

17 Summa theol., I, 3, 3: Sed materia individualis, cum accidentibus omnibus individuantibus ipsam, non cadit in definitione speciei: non enim cadunt in definitione hominis hae carnes et haec ossa, aut albedo vel nigredo, vel aliquid huiusmodi. Unde hae carnes et haec ossa et accidentia designantia hanc materiam, non concluduntur in humanitate. Et tamen in eo quod est homo, includuntur: unde id quod est homo, habet in se aliquid quod non habet humanitas".

18 Summa theol., i, 57, 2: "Tal como el hombre conoce todas las clases de cosas mediante diversas facultades cognoscitivas, a saber, las cosas universales e inmateriales mediante el intelecto y las cosas singulares y corporales mediante los sentidos, así el ángel conoce las unas y las otras por obra de una sola facultad intelectiva". 
La poesía medieval, producto de alquimia hecho de la fusión de un elemento literal y uno alegórico, debió presentarse a Dante como el símbolo de la fusión del elemento sensitivo y del intelectivo en el conocimiento. Pero sólo al ángel, y no al hombre, le es dado incorporar ambas formas de la aprehensión de la realidad -la de lo singular y la de lo universal- en un solo acto intelectivo; y, asimismo, sólo el poeta, y no el científico o el didacta, tiene la posibilidad de fundir ambos elementos en un solo acto creador. La superposición de sentido literal y de sentido alegórico, de belleza y de doctrina, que caracteriza, entre otras, a la poesía dantesca, le confiere, tanto desde el punto de vista del saber como desde el de la creación artística, una perfección análoga a la de la ciencia de los ángeles y la señala como la más alta forma del saber concedida al hombre. 